\title{
Longitudinal State-Level Effects on Change in Body Mass Index Among US Middle-Aged and Older Adults in the USA
}

Cheng-Chia Chen ${ }^{a}$, Dong-Chul Seo ${ }^{b}$, and Hsien-Chang Lin ${ }^{b}$

aDepartment of Public Health, University of Illinois, Springfield, IL, USA

${ }^{b}$ Department of Applied Health Science, Indiana University, Bloomington, IN, USA

\begin{abstract}
Objective: The purpose of this longitudinal study was to examine the effects of state-level socioeconomic status (SES), the density of fast food restaurants, and walking to work on body mass index (BMI) among US adults aged 50 years and older. The study sought further to account for the interaction effects of three different hierarchical levels of variables including time-varying variables and time-invariant variables such as individual and state-level variables. Confounding related to environmental/neighbourhood effects was controlled for through sample selection.
\end{abstract}

Methods: Data were drawn from the 2000-2010 Health and Retirement Study (HRS) and the 2010 US Census. HRS survey participants aged 50 years and older in 2000, residing in the same census tract during $2000-2010(N=6,156)$ comprised the study sample. A three-level growth model was fit to BMI trajectories.

Results: BMI significantly increased over time showing both a linear and quadratic decelerating trajectory $(p<.001)$ where BMI grew faster among sampled adults in their early 50 s. Women living in US states with a lower state-level SES had higher BMIs while men living in states with higher state-level SES had a higher BMI $(b=-0.242, p=.013)$. In states with a higher proportion of people who walked to work, Hispanics had higher BMIs at baseline and a lower BMI growth rate, compared with non-Hispanic whites $(b=-0.033, p<.001)$.

Conclusions: Obesity interventions specific to adults aged 50 and older require greater emphasis. Potential health inequalities regarding weight gain can be ameliorated through tailoring interventions based on sex, environmental, and state-level SES influences.

\section{Keywords:}

Obesity; body mass index; obesogenic environment; socioeconomic status; multilevel analysis: USA

\section{Corresponding Author:}

Dong-Chul Seo, Department of Applied Health Science, Indiana University School of Public Health, 1025 E. Seventh Street, Bloomington, Indiana, 47405-7109, USA

E-mail: seo@indiana.edu 


\section{Introduction}

Obesity is a well-known public health issue both in the USA and worldwide (Flegal et al., 2012; Popkin et al., 2012). Middle-aged and older adults show the highest obesity rate compared with those of other age groups regardless of sex and race/ethnicity (Flegal et al., 2012). A strong body of evidence shows that clinical consequences of overweight and obesity, such as type 2 diabetes, are more serious and particularly problematic for older adults (Han et al., 2011). Obesity coupled with aging increases healthcare service expenditure (Han et al., 2011), which enlarges the healthcare burden to society. Therefore, researchers continue to investigate a variety of obesity determinants such as built environment or obesogentic environment (e.g., access to fast food outlets and neighbourhood walkability), as well as micro- and macro-level socio-economic status (SES) to tackle this issue (Lakerveld et al., 2012), especially for middleaged and older adults.

The built environment can be considered all buildings and space created, or modified to form the physical characteristics of a community. It may include a variety of items such as roads, homes, buildings, parks, and recreation areas (Centers for Disease Control and Prevention, 2013) An obesogenic environment refers to an environment which is defined as the "sum of influences that the surroundings, opportunities, or conditions of life have on promoting obesity in individuals or populations." (Swinburn et al., 1999). Although many obesogenic environment studies have been conducted, the association of obesogenic environments and obesity has not been fully studied due to the complexity of measuring options and potential confounding effects from the interaction between environmental and socioeconomic factors (Kirk et al., 2010), especially for middle-aged and older adults. Thus, a better understanding of obesity determinants for adults aged 50 and above including obesogenic/socioeconomic factors is necessary to help reduce the high obesity prevalence and alleviate the overall burden of obesity-related diseases and associated health care costs.

Although there have been a few longitudinal studies concerning BMI trajectories among middle-aged and older adults, their results are inconclusive. One longitudinal study reports that BMI, on average, continues to increase and plateaus around 60-70 years of age (Villareal et al., 2005). Another longitudinal study reports that BMI increases up to 75 years of age (Botoseneanu and Liang, 2010). Furthermore, research findings are unclear on sex differences in weight changes among middle-aged and older adults (Botoseneanu et al., 2010) and on the associations between obesity rates and macro-level environmental variables such as food outlets or walking environment in a geographic area (Ding and Gebel, 2012; Fan et al., 2011; Ruel et al., 2010; Winkleby and Cubbin, 2003).

Moreover, previous studies have revealed that obesity or BMI trends varied across geographic areas such as states and regions (Wang and Beydoun, 2007). States are unique entities with their own governance and authority to legislate state-specific laws and health policies. While some studies have examined the associations between weight gain and macrolevel environmental variables such as density of fast food restaurants and proportion of people who walk to work among younger adults, few studies have examined how these factors affect adults over the age of 50 (Mujahid et al., 2005; Pucher et al., 2010; Ruel et al., 2010). In addition, there are very limited numbers of studies regarding micro-level obesity factors (e.g., 
racial/ethnic segregation and sex) and their moderating effects on the association between macro-level obesity determinants (e.g., state-level SES) and BMI (Mobley et al., 2006).

All of these findings in the literature converge on the need to investigate the effect of state-level variables on the trends of BMI among a nationally representative sample of middleaged and older adults. Given the aforementioned literature findings, albeit some are limited, our research questions were as follows:

(1) How do longitudinal trajectory patterns of BMI differ by sex and increase over time in a sample of US adults aged 50 years or older?

(2) How are state-level variables (i.e., state-level SES, density of fast food restaurants, and proportion of people who walk to work) associated with longitudinal trajectory patterns of BMI?

(3) Do the effects of the state-level variables on individuals' BMI trajectories vary by demographics?

(4) Does sex or race/ethnicity have a moderating effect on the association between state-level SES and obesity?

\section{Methods}

\section{Data}

The data used for this study were drawn from the US Health and Retirement Study (HRS), a nationwide longitudinal study of health, retirement and aging among US adults aged over 50 years. It has been a leading source for information on the health and economic well-being of the aforementioned age group with funding support by the US National Institute on Aging (NIA U01AG009740) and the Social Security Administration (Health and Retirement Study [HRS], 2016). The HRS is an ongoing biennial research project that has been collecting multiple waves of data since 1990. Moreover, it takes two years to complete data collection for a specific wave of data in order to obtain intensive demographic and health related data (e.g., age, sex, education, race/ethnicity, marital status, physical and mental health status, BMI). Therefore, data collected from 1990 to 1992 were considered the first wave of data. The HRS has collected twelve waves of data (i.e., from the first wave [1990-1992] to the twelfth wave [2012-2014]) since the inception of the study.

The HRS survey response rates (2000-2010) ranged from $81.0 \%(2008-2010)$ to $88.9 \%$ (2004-2006) (HRS, 2017). The investigators linked the data (2000-2010) to the 2010 U.S. Census data based on the census tract information of the HRS respondents. Although census data were available in 2000 and 2010, only the 'restricted' geographic information system (GIS) data regarding HRS subjects' census tract information from 2010 Census were accessible to the researchers in the present study. Our research team had to develop an extensive and secure data protection plan to get the approval from the HRS to access the above GIS data. Therefore, 2010 Census data and 2010 HRS GIS information were linked for the data analyses. The linkage allowed for investigation of the impact of statewide percentage of people who walk to work and density of limited-service restaurants, which is a proxy measure for density of fast food restaurants, on study participants' BMI trajectories. Permission to use the participants' census 
tract information was obtained from the HRS and the study protocols were approved by the Indiana University Institutional Review Board.

\section{Study sample}

Our goal was to select HRS respondents living in the same census tract from 2000 to 2010, which gave this study a good control of each participant's living environment and surrounding neighborhood. This sample selection approach minimised a variety of confounding effects due to exposure to different environmental and neighborhood factors (e.g., density of fast food restaurants and neighborhood walkability). Figure 1 below illustrates each step of the sample selection process.

Based on the above selection criterion, the initial sample consisted of 7,664 participants. Since the HRS recruited study participants aged 50 years and older and their spouses of any age, some HRS respondents' spouses were less than 50 years old. Thus, we excluded 225 primary participants' spouses who were ineligible because they were younger than 50 as of Year 2000. Also excluded were the 622 individuals who died between 2000 and 2010. Another 556 respondents were excluded due to incomplete surveys resulting in missing data. Our analyses were limited to non-Hispanic whites, non-Hispanic blacks and Hispanics due to a very small percentage of people reporting their race/ethnicity as "others," therefore, an additional 102 subjects were eliminated. Finally, three multivariate outliers determined by Mahalanobis distances were also excluded.

Analysis was conducted based on listwise deletion for cases with missing data which did not show systematic pattern according to Little's MCAR (Missing Completely at Random) test (Dickson and Flynn, 2008; Little, 1998; Little and Rubin, 2002; Outhwaite and Turner, 2007; Seo and $\mathrm{Li}, 2009)$. In terms of quantity, less than $10 \%$ of the study participants had missing data. Thus, potential loss of statistical power due to the exclusion of missing data may not have biased estimation (Acock, 2015). In summary, the sample selection process resulted in the final study sample of 6,156 participants at baseline who were followed for ten years.

$$
<<\text { Insert Figure } 1 \text { about Here>> }
$$

\section{Variables and measurement}

The dependent variable in this study was BMI computed by weight (lb)/ [height (in)] ${ }^{2} \times 703$ using self-reported weight and height information. There are six waves of BMI data from 2000 to 2010. The independent variables are categorised into three different hierarchical levels: time-varying individual changes (Level 1 variables), time-invariant individual variables (Level 2 variables), and time-invariant state-level variables (Level 3 variables). Year was used as a time variable, which was coded from 0 to 10. Level 2 variables included age in 2000, number of years of schooling completed, sex, and race/ethnicity. Sex was coded as 0 for men and 1 for women. Race/ethnicity was coded as 0 for non-Hispanic whites, 1 for non-Hispanic blacks, and 2 for Hispanics. Level 3 variables included state-level SES, density of fast food restaurants (per 100,000 people), and percent of people who walked to work from the census data in 2010 . All of Level 3 variables were grand-mean centered to facilitate interpretation of multilevel models 
(Hox, 2002). The state-level rather than census tract level was used as the unit of analysis because (1) the states may have unique policies with their own governing power and influence, and (2) there were sufficient sample sizes at the state level, not at the census tract level, to provide reliable estimates for the parameters in multilevel modeling (Hox, 2002).

The state-level SES was computed by taking the mean of SES indices of all census tracts in each state. The SES indices were based on median household income, educational attainment, and poverty defined by the U.S. Census Bureau (Gomez et al., 2007). Moreover, the state-level SES indices were reverse coded so that a high score indicated a higher level of SES. Consequently, the state-level SES represented a composite scale score reflecting socioeconomic status for each state and ranges from a score of 3 (the worst) to 12 (the best).

In addition, limited-service restaurants from the census data have been used as a proxy measure for fast food restaurants (Lopez, 2007). Thus, in this study, state-level density of fast food restaurants was calculated from the number of limited-service restaurants divided by the total population in each state. Finally, state-level proportion of people who walk to work is a measure of built environment for physical activity (Glazier et al., 2014; Pucher et al., 2010). In other words, this variable can be referred to as an obesogenic environment of physical inactivity (Waine, 2005). A higher proportion of people who walk to work indicates an environment with better walkability that encourages people to walk (Lovasi et al., 2009; Smith et al., 2008). State-level proportions of people who walked to work were computed by aggregating percentage of people who walked to work at the census-tract level.

\section{Statistical analysis}

We fitted three-level hierarchical linear models using HLM 7.0 (Scientific Software International, Lincolnwood, IL, USA) to analyse longitudinal trajectories of BMI over ten years with the different levels of impact from temporal effects (the time-varying variable [i.e., BMI] at Level 1), individual sociodemographic characteristics (time-invariant variables [e.g., sex, race/ethnicity] at Level 2), and state-level characteristics such as state-level SES, density of fast food restaurants, and proportion of people who walk to work (time-invariant variables [i.e., state-level SES, density of fast food restaurants, and proportion of people who walk to work] at Level 3) where all 50 states had data for our analyses. HLM 7.0 statistical software was used as it provides great flexibility in capturing the changing patterns from the repeated measures within individuals and appropriately accounts for correlated errors within nested units of data collection (Raudenbush and Bryk, 2002).

Our modeling strategies were guided by the modeling steps in multilevel modeling literature (Raudenbush et al., 2002). Full maximum likelihood estimation was used to describe the fit of both fixed effects and variance components. Log-likelihood ratio tests for model chisquare differences were used for model selection decisions. As the weighting criteria in the HRS were not based on the dependent variable (i.e., BMI), but rather the independent variables in the present study, sampling weights were not applied for analysis. According to Winship and Radbill (1994), "When sampling weights are only a function of independent variables included in the model being estimated, unweighted ordinary least squares (OLS) regression will be the appropriate course to take." 


\section{Results}

Table 1 outlines the baseline descriptive statistics of the study sample. Of the 6,156 participants, $61.6 \%$ were female; $79.0 \%$ were non-Hispanic whites. The minimum age was 50 years, the maximum age was 93 years at baseline (i.e., 2000), and the mean age was 64.5 years $(S D=7.9)$. The mean BMI was $27.5(S D=5.1)$ in 2000 . The mean state-level density of fast food restaurants was 89 per 100,000 people $(S D=1.40)$ and the mean state-level percentage of people who walked to work was 3.45\% $(S D=1.56)$. Figure 2 illustrates BMI trajectories by sex over the ten years. Men consistently showed a higher level of BMI than women.

\section{$<$ Insert Table 1 and Figure 2 around Here $>>$}

Table 2 illustrates the results from three-level hierarchical linear models. The first intraclass correlation (ICC) coefficient was $0.81(25.27$ / [3.56+25.27+2.34]), which means that $81 \%$ of the total variation in BMI trajectory was attributable to differences between different individuals. The second ICC was $0.08(2.34 /[3.56+25.27+2.34])$, which means that $8 \%$ of the total variation in BMI trajectory was attributable to differences between different states. Both ICCs justified the use of multilevel models. The unconditional growth model (Model 2) showed significant linear and quadratic decelerating growth in BMI. Women had a lower initial BMI $(p<.001)$, but showed a faster linear growth rate of BMI $(p<.001)$ than men in Model 3 and 4 ( $b=-0.669$ and $b=-0.668$, respectively), supporting the first hypothesis that individual trajectory patterns differ by sex and tend to increase over time in this this aged 50 and older.

The second hypothesis that state-level variables are associated with individuals' BMI trajectories was partially supported. When sex differences were not accounted for, BMIs at baseline and their trajectories did not vary by the state-level SES. Neither the state-level density of fast food restaurants nor the proportion of people who walked to work was significantly associated with individuals' BMI trajectories. However, the effect of state-level SES on individual's BMI was significantly different by sex $(b=-0.242, p=.013)$ in Model 4. As shown in Figure 3, sex moderated the effect of state-level SES on BMI. There was a gradient in BMI across levels of state-level SES for both women and men, but in the opposite direction. Based on the study results, BMI was similar for men and women in states with low SES, but was increasingly divergent, where BMI was higher for men and lower for women, as state-level SES increased.

\section{$<<$ Insert Table 2 and Figure 3 around Here $>>$}

The 3-way interaction between year, Hispanics (vs. non-Hispanic whites), and state-level percentage of people who walked to work was significant $(b=-0.033, p<.001)$. To probe this interaction, the relations between the three variables were plotted in Figure 4. Hispanics living in states with a lower proportion of people who walked to work showed a higher growth in BMI over time than Hispanics living in states with a higher proportion of people who walked to work. On the other hand, the other 3-way interactions involving Level-3 variables were not significant. Based on our findings, the third hypothesis that the effects of the three state-level variables on individuals' BMI trajectories vary depending on demographic factors was partially supported. 
$<<$ Insert Figure 4 about Here >

\section{Discussion}

The findings of this study contribute to existing literature on BMI-related health disparities by investigating cross-level interactions between micro-level and macro-level obesity determinants in a nationally representative sample of U.S. middle-aged and older adults. This study investigated when, where, and for whom certain obesogenic environments are more influential to weight gain and obesity using a longitudinal three-level hierarchical linear modeling approach. It examined multiple contextual relationships between time, state-level SES and obesogenic environment, individuals' demographic factors, and BMI changes over a 10year period of time among U.S. adults aged 50 and above.

\section{Aging and $B M I$}

Findings revealed evidence that individuals' BMIs increase over time at a slightly decelerating rate among people aged 50 and above. It is consistent with the results from Botoseneanu and Liang (2010), and further strengthens the evidence that suggests both male and female adults continue to gain weight, although more slowly, as they age. Knowing that BMI trajectory for older persons is growing at a decelerating rate, the obesity prevention effort should focus more on late middle-aged and young older. Proactive and aggressive actions should be taken to reduce obesity prevalence for this age group.

\section{State-level SES and BMI}

Findings also suggest that there is a sex difference in the influence of state-level SES on BMI trajectories, which supports previous research findings that women living in more socioeconomically disadvantaged areas have higher BMIs (Mujahid et al., 2005). A possible explanation is that women might perceive the influence from their surrounding environment (e.g., perceived safety to go for a walk) differently from men. Such differential perception has been reported to be associated with different health outcomes (Bengoechea et al., 2005). Another possible explanation is that women might be more dependent than men upon resources from the surrounding environment to maintain their effort to control weight (Stafford et al., 2005). Women are usually more connected than men to the local environment and spend more time on food acquisition/preparation and shopping; thus, women's dependence on surrounding environment tends to be stronger than men (Matheson et al., 2008). Women living in socially disadvantaged states might be particularly vulnerable to unhealthy conditions (Winkleby et al., 2003). By contrast, men who lived in states with higher state-level SES had higher BMIs. This phenomenon may have to do with a lack of time for exercise, sedentary work environment, or more opportunities to eat at restaurants for men compared with women (Chang and Lauderdale, 2005). These findings imply that obesity prevention interventions and initiatives targeted to middle-aged or older adults need to place greater emphasis on services for women in states with low SES and services for men in states 
with high SES. More research is warranted to investigate the mechanisms by which state-level socioeconomic status affects weight gains differently between men and women.

\section{Obesogenic Environment and BMI}

Our findings indicate that state-level density of fast food restaurants and proportions of people who walk to work might not be associated with individual's BMI or increases in obesity among people aged 50 and older. However, it deserves mention that there was a difference between racial/ethnic groups in the way that proportions of people who walked to work affected longitudinal BMI changes. As mentioned earlier, the percentage of people who walk to work represents a measure of obesogenic environment of physical inactivity or area walkability (Glazier et al., 2014; Lovasi et al., 2009; Pucher, 2010).

More specifically, Hispanics living in states with a higher proportion of people who walked to work had a lower BMI growth rate. According to a recent American Community Survey Report (McKenzie, 2014), Hispanics comprise one of the top two racial/ethnic groups that have the highest percentages of people who walk to work. The relatively high percentages might be due to financial necessity, lower rates of car ownership, or may be more likely to live near walkable urban areas (Besser and Dannenberg, 2005). Plaut (2004) also pointed out that people who walk to work usually have lower incomes and are less educated, indicators which are usually associated with a higher BMI (Besser et al., 2005). The finding of the present study indicates that higher area walkability may be beneficial to weight control at the population level. Given that Hispanics overall have higher obesity rates than other racial/ethnic groups and that the fastest-growing segment of the US population is Hispanic, this is a significant piece of information that emphasises the potential for regular physical activity to promote weight control among Hispanics. Even without vigorous-intensity physical activity or lengthy workouts people may be able to lose weight or decelerate weight gains with consistent physical activity (Haskell et al., 2007). Another implication of this finding is the importance of the built environment. In order to improve the built environment for physical activity, policies that encourage development of a more walkable environment need to be implemented and promoted. State governments need to consider investing in age friendly walkability programmes and pedestrian-oriented commercial spaces. For instance, a greater integration of land use and street connectivity in community planning and housing development could bring commercial and residential areas closer to remove barriers to walking (Saelens and Handy, 2008).

With regard to the density of fast food restaurants, the hypothesis that such a statelevel variable would be associated with longitudinal trajectory patterns of BMI was not supported. Actually, there are contradictory findings on the relationship between the density of fast food restaurants and an increase in body weight of people living in the respective geographical area. Some studies reported significant associations between density of fast food restaurants and obesity but they were conducted either with cross-sectional designs (Fleischhacker et al., 2011) or in self-selected areas, which may have introduced selection bias (Ding et al., 2012). By contrast, a number of other studies did not find a significant relationship between the two (Lopez, 2007). Given that no population-based studies to date have revealed the extent to which the density of fast food restaurants is linked to the frequency of individual 
visits to fast food restaurants or caloric intake among patrons in this 50-plus-year-old population, future research is warranted to investigate these immediate connections that may lead to weight gains as well as to corroborate the finding of the present study regarding the longitudinal effect of the density of fast food restaurants in this population (Pérez-Escamilla et al., 2012).

\section{Limitations}

Our findings should be interpreted in the light of several study limitations. First, BMIs for HRS respondents were calculated from self-reported weights and heights. Underestimation of weight and overestimation of height might have confounded our findings (Gunnell et al., 2000). However, the longitudinal design in the present study may have compensated for the bias because comparing the same person's weight and height over time is likely to minimise the errors from self-reported figures (Bowman and DeLucia, 1992). Second, over the study period, some state-level data may have varied but the present study treated state-level data as static. Thus, any possible differential influence of changes in the state-level data might have confounded our findings. Third, the death of some cohort participants during the study period, albeit a small proportion of the cohort, might have introduced bias.

\section{Conclusion}

Despite the above limitations, this study contributes to the literature by shedding light on the heterogeneity of BMI change trajectories during the transition to older adulthood. To our best knowledge, this study was one of the first attempts to investigate BMI trajectories in a US representative sample of adults aged 50 years and older using three-level growth models where cross-level interactions were probed. BMI significantly increased over time showing a quadratic decelerating trajectory (i.e., growing faster when people were at their younger ages). Thus, more intensive obesity prevention interventions should be held for middle-aged adults because BMI growth rates peak at those ages. In addition, evidence suggests that health inequality may exist due to the variation in weight increasing patterns from different sex, environmental, and socioeconomic factors. In order to decrease health inequality, public health professionals and policy makers should take into account the aforementioned factors carefully and create more effective obesity interventions such as providing better walking environments. Finally, our study expands existing research topics on a macro-level obesity determinant by examining the impact of obesogenic environments. Future studies may need to investigate macro-level obesity factors using different measures of obesogenic environment and attempting to track $\mathrm{BMI}$ for a longer time period.

\section{Acknowledgement}

The data use of the Health and Retirement Study (HRS) respondents' census tract information was approved by the HRS.

\section{Disclosure statement}


The authors declare no conflict of interest. 


\section{References}

Acock, AC (2005) Working with missing values. Journal of Marriage and Family 67(4): 10121028.

Bengoechea EG, Spence JC and McGannon KR (2005) Gender differences in perceived environmental correlates of physical activity. International Journal of Behavioral Nutrition and Physical Activity 2(1): 12-20.

Besser LM and Dannenberg AL (2005) Walking to public transit: Steps to help meet physical activity recommendations. American Journal of Preventive Medicine 29(4): 273-280.

Botoseneanu A and Liang J (2010) Social stratification of body weight trajectory in middle-age and older Americans: Results from a 14-year longitudinal study. Journal of Aging and Health 23(3): 454-480.

Bowman RL and DeLucia JL (1992) Accuracy of self-reported weight: A meta-analysis. Behavior Therapy 23(4): 637-655.

Centers for Disease Control and Prevention. (2013, August 14). Healthy places terminology from https://www.cdc.gov/healthyplaces/terminology.htm

Chang VW and Lauderdale DS (2005) Income disparities in body mass index and obesity in the United States, 1971-2002. Archives of Internal Medicine 165(18): 2122-2128.

Dickson, GL, and Flynn, L (eds) (2008) Nursing policy research: Turning evidence-based research into health policy. New York: Springer Publishing Company.

Ding D and Gebel K (2012) Built environment, physical activity, and obesity: What have we learned from reviewing the literature? Health \& Place 18(1): 100-105.

Fan AZ, Strasser S, Zhang X, et al. (2011) State-level socioeconomic factors are associated with current depression among US adults in 2006 and 2008. Journal of Public Health and Epidemiology 3(10): 462-470.

Flegal KM, Carroll MD, Kit BK, et al. (2012) Prevalence of obesity and trends in the distribution of body mass index among US adults, 1999-2010. Journal of the American Medical Association 307(5): 491-497.

Fleischhacker S, Evenson K, Rodriguez D, et al. (2011) A systematic review of fast food access studies. Obesity Reviews 12(5): e460-e471.

Glazier, RH, Weyman, JT, Creatore, MI, et al. (2008). Development and validation of an urban walkability index for Toronto, Canada. Canadian Journal of Diabetes, 32(4): 1-22.

Gomez SL, D O'Malley C, Stroup A, et al. (2007) Longitudinal, population-based study of racial/ethnic differences in colorectal cancer survival: Impact of neighborhood socioeconomic status, treatment and comorbidity. BMC Cancer 7(1): 193-211.

Gunnell D, Berney L, Holland P, et al. (2000) How accurately are height, weight and leg length reported by the elderly, and how closely are they related to measurements recorded in childhood? International Journal of Epidemiology 29(3): 456-464.

Han T, Tajar A and Lean M (2011) Obesity and weight management in the elderly. British Medical Bulletin 97(1): 169-196.

Haskell WL, Lee I-M, Pate RR, et al. (2007) Physical activity and public health: Updated recommendation for adults from the American College of Sports Medicine and the American Heart Association. Circulation 116(9): 1081-1093. 
Health and Retirement Study (2016) Getting started: How to use this site. Retrieved from https://hrs.isr.umich.edu/about/how-to-use-this-site

Hox J (2002) Multilevel analysis: Techniques and applications. (2nd ed) New York: Routledge.

Kirk, SF, Penney, T, and McHugh, TL (2010) Characterizing the obesogenic environment: The state of the evidence with directions for future research. Obesity Reviews 11(2): 109117.

Lakerveld J, Brug J, Bot, S et al. (2012) Sustainable prevention of obesity through integrated strategies: The SPOTLIGHT project's conceptual framework and design. BMC Public Health 12(1): 793-800.

Little RJ (1988) A test of missing completely at random for multivariate data with missing values. Journal of the American Statistical Association 83(404): 1198-1202.

Little RJ and Rubin DB (2002) Statistical analysis with missing data. Hoboken, NJ: John Wiley \& Sons.

Lopez RP (2007) Neighborhood risk factors for obesity. Obesity 15(8): 2111-2119.

Lovasi, GS, Hutson, MA, Guerra, M et al. (2009). Built environments and obesity in disadvantaged populations. Epidemiologic Reviews 31(1): 7-20.

Matheson Fl, Moineddin R and Glazier RH (2008) The weight of place: A multilevel analysis of gender, neighborhood material deprivation, and body mass index among Canadian adults. Social Science \& Medicine 66(3): 675-690.

McKenzie B (2014) Modes less traveled-bicycling and walking to work in the United States: 2008-2012. Retrieved April 11, 2016, from U.S. Census Bureau Web site: http://www.census.gov/prod/2014pubs/acs-25.pdf

Mobley, LR, Root, ED., and Finkelstein, EA et al (2006). Environment, obesity, and cardiovascular disease risk in low-income women. American Journal of Preventive Medicine 30(4): 327-332.

Mujahid MS, Roux AV, Borrell LN, et al. (2005) Cross-sectional and longitudinal associations of BMI with socioeconomic characteristics. Obesity Research 13(8): 1412-1421.

Outhwaite, W and Turner, S (eds) (2007) The SAGE handbook of social science methodology. Thousand Oaks, CA: SAGE.

Pérez-Escamilla R, Obbagy JE, Altman JM, et al. (2012) Dietary energy density and body weight in adults and children: A systematic review. Journal of the Academy of Nutrition and Dietetics 112(5): 671-684.

Plaut PO (2004) Non-commuters: The people who walk to work or work at home. Transportation 31(2): 229-255.

Popkin, BM, Adair, LS, and Ng, SW (2012). Global nutrition transition and the pandemic of obesity in developing countries. Nutrition Reviews 70(1): 3-21.

Pucher J, Buehler R, Bassett DR, et al. (2010) Walking and cycling to health: A comparative analysis of city, state, and international data. American Journal of Public Health 100(10): 1986-1992.

Raudenbush SW and Bryk AS (2002) Hierarchical linear models: Applications and data analysis methods (2nd ed) Thousand Oaks, CA: SAGE.

Ruel E, Reither EN, Robert SA, et al. (2010) Neighborhood effects on BMI trends: Examining BMI trajectories for Black and White women. Health \& Place 16(2): 191-198. 
Saelens BE and Handy SL (2008) Built environment correlates of walking: A review. Medicine and Science in Sports and Exercise 40(7 Suppl): S550-S566.

Seo, DC and Li, K (2009) Effects of college climate on students' binge drinking: Hierarchical generalized linear model. Annals of Behavioral Medicine 38(3): 262-268.

Smith KR, Brown BB, Yamada I, et al. (2008) Walkability and body mass index: Density, design, and new diversity measures. American Journal of Preventive Medicine 35(3): 237-244.

Stafford M, Cummins S, Macintyre S, et al. (2005) Gender differences in the associations between health and neighbourhood environment. Social Science \& Medicine 60(8): 1681-1692.

Swinburn, B, Egger, G, \& Raza, F (1999). Dissecting obesogenic environments: The development and application of a framework for identifying and prioritizing environmental interventions for obesity. Preventive Medicine 29(6): 563-570.

Villareal DT, Apovian CM, Kushner RF, et al. (2005) Obesity in older adults: Technical review and position statement of the American Society for Nutrition and NAASO, The Obesity Society. Obesity Research 13(11): 1849-1863.

Waine, C (2005) The metabolic syndrome: The whole is more than the sum of its parts. Journal of Men's Health \& Gender 2(2): 170-178.

Wang Y and Beydoun MA (2007) The obesity epidemic in the United States-gender, age, socioeconomic, racial/ethnic, and geographic characteristics: A systematic review and meta-regression analysis. Epidemiologic Reviews 29(1): 6-28.

Winkleby MA and Cubbin C (2003) Influence of individual and neighbourhood socioeconomic status on mortality among black, Mexican-American, and white women and men in the United States. Journal of Epidemiology and Community Health 57(6): 444-452.

Winship C and Radbill L (1994) Sampling weights and regression analysis. Sociological Methods \& Research 23(2): 230-257. 


\section{Figure Legends}

Figure 1. Flow chart of the study sample selection

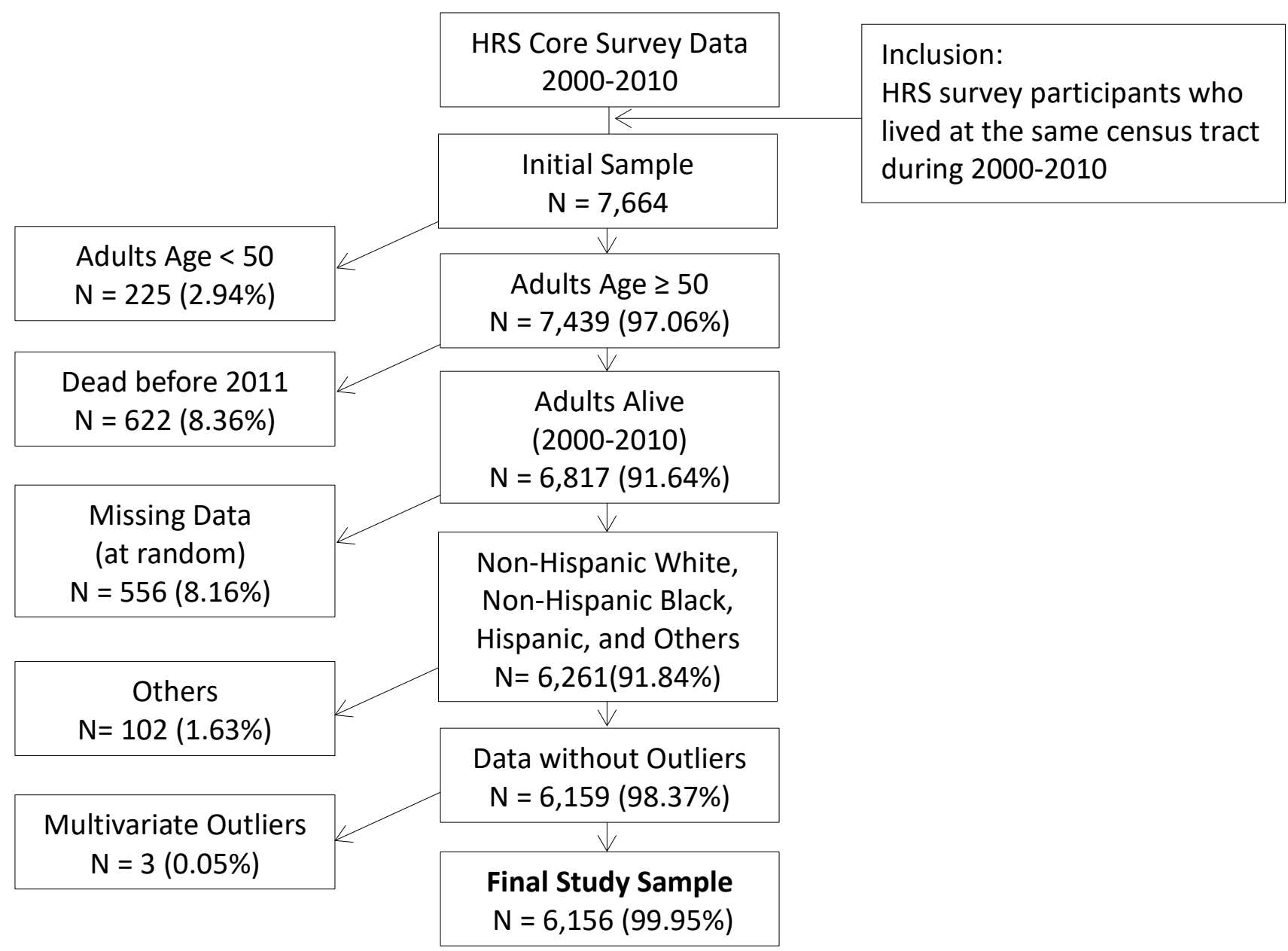


Figure 2. Trends in body mass index from 2000 to 2010: Results of 6 waves of data from Health and Retirement Study (HRS 2016).<smiles>[107Po]</smiles>

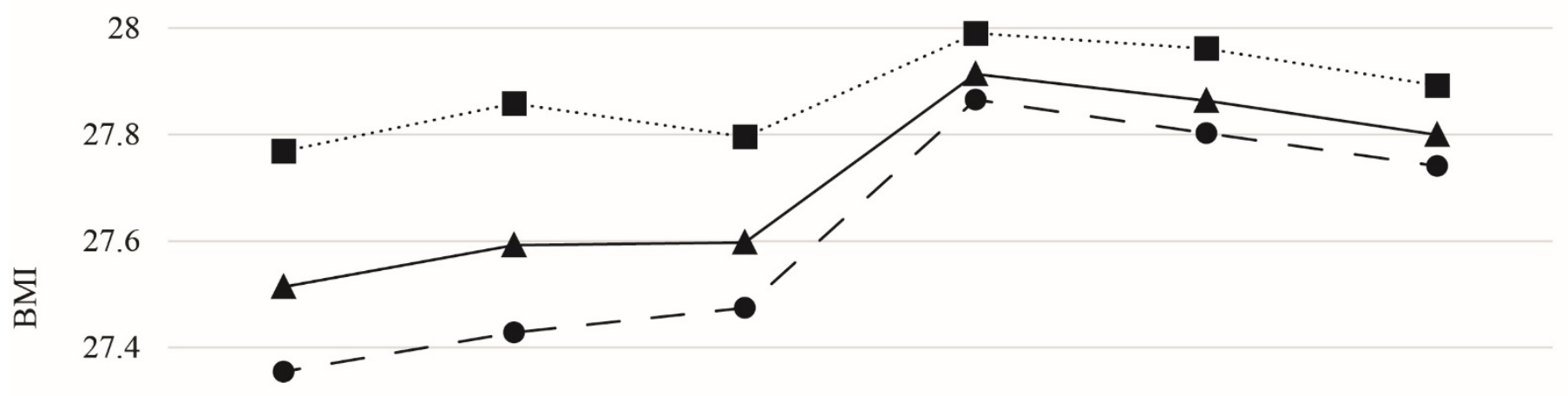

27.2

27

\begin{tabular}{|c|c|c|c|c|c|c|}
\hline 2000 & 2002 & 2004 & 2006 & 2008 & 2010 & Year \\
\hline$(64.5)$ & $(66.5)$ & $(68.5)$ & $(70.5)$ & $(72.5)$ & $(74.5)$ & (Average age of all participants) \\
\hline
\end{tabular}

....... Men's average BMI

Average BMI of all participants

- Women's average BMI 
Figure 3. Cross-level interaction between sex and state-level socioeconomic status for BMI (HRS 2016).

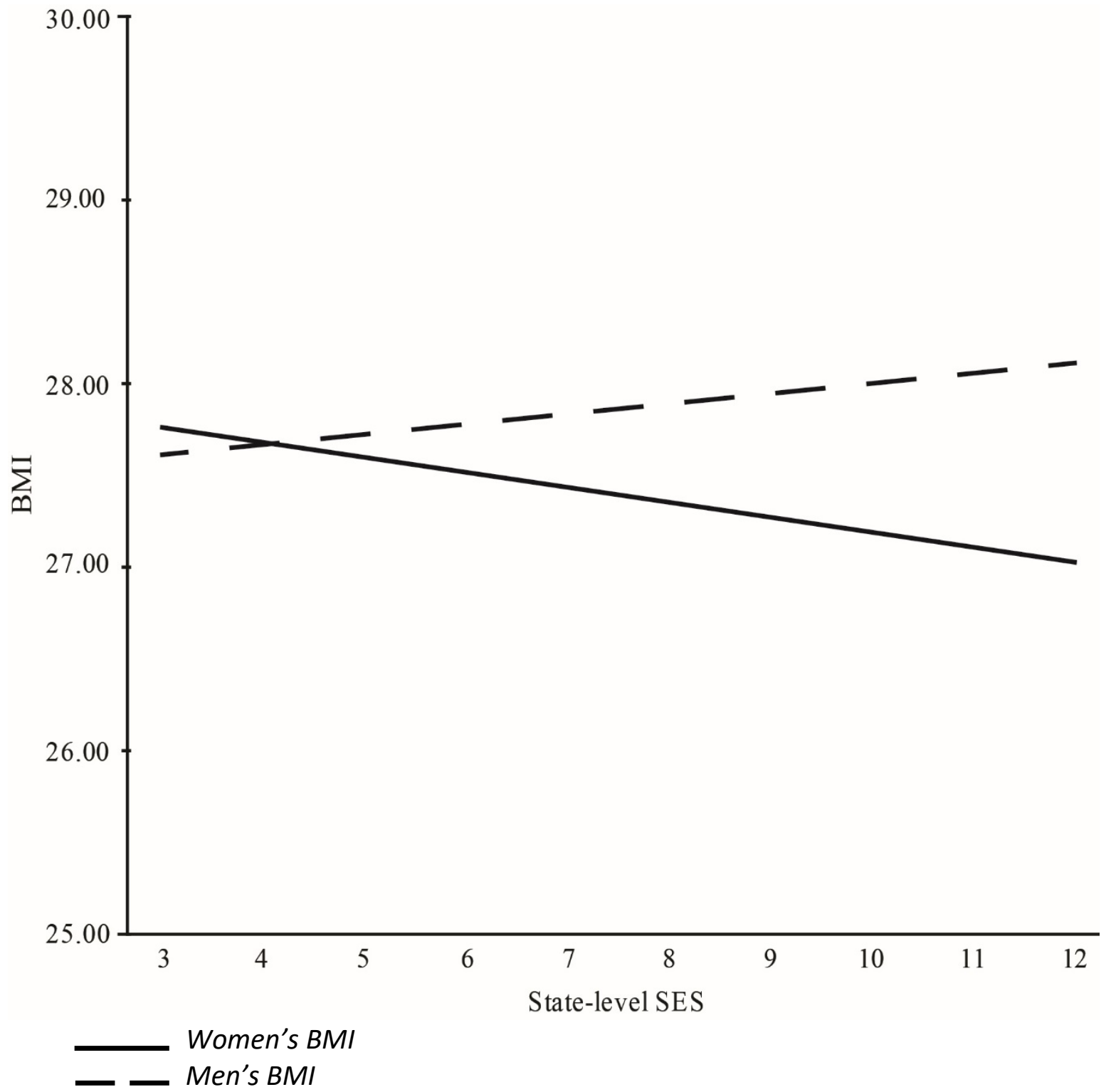

Note: State-level SES is a composite scale score reflecting socioeconomic status for each state and ranges from 3 (the worst) to 12 (the best). 
Figure 4. Three-way cross-level interaction between year, Hispanic (vs. Non-Hispanic white), and the proportion of people who walk to work on BMI trajectories (HRS, 2016).

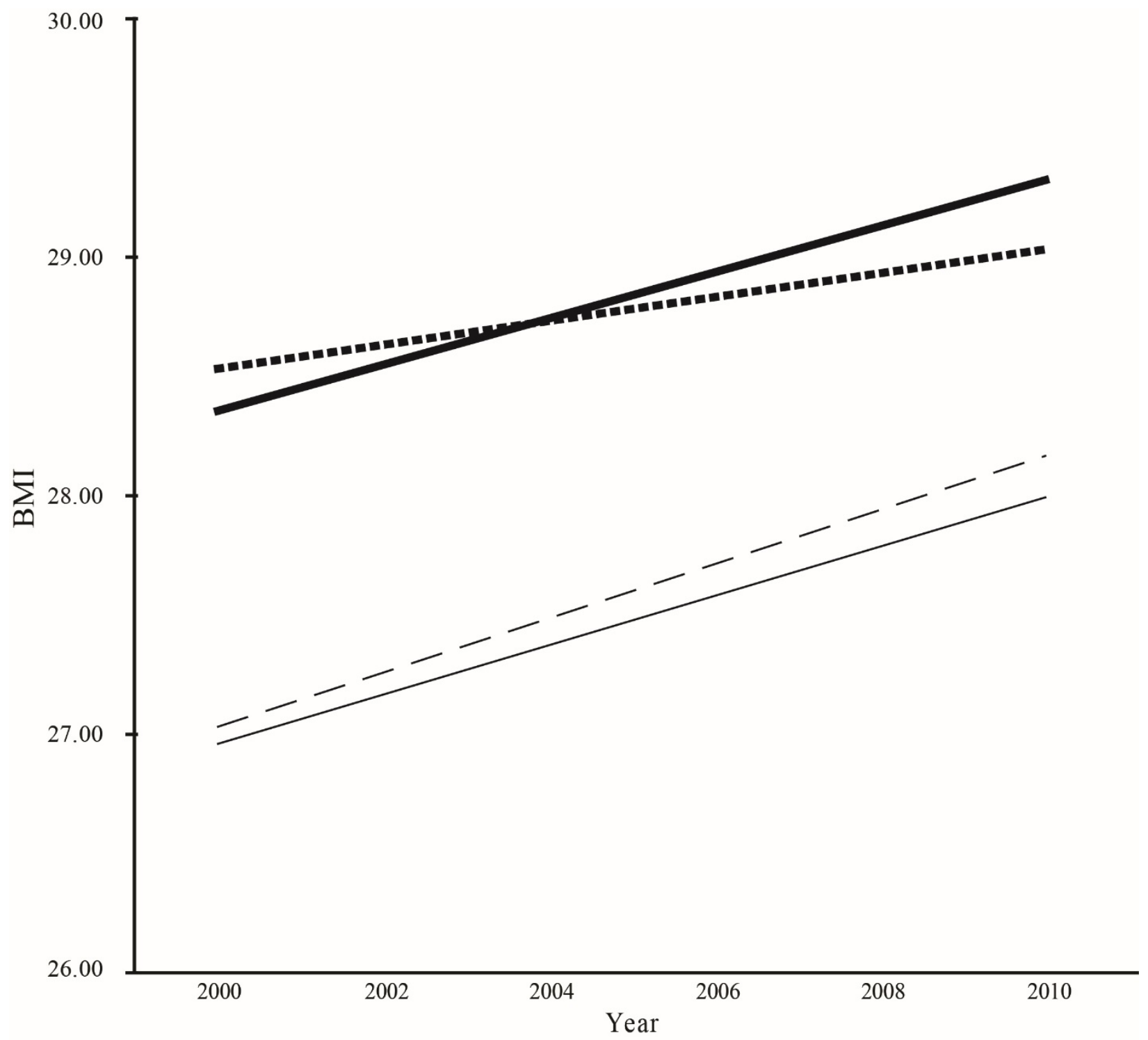

Hispanics' average BMI for those who live in the states with a lower percentage of people who walk to work (25th percentile)

1. . . Hispanics' average BMI for those who live in the states with a higher percentage of people who walk to work (75th percentile)

- - - Average BMI of non-Hispanic whites who live in the states with higher percentage of people who walk to work (75th percentile)

Average BMI of non-Hispanic whites who live in the states with lower percentage of people who work to work (25th percentile) 
Table 1 Baseline characteristics of the study sample $(n=6,156$, ages $\geq 50)$, Health \& Retirement Study ${ }^{\dagger}$

\begin{tabular}{|c|c|c|}
\hline Variable & $n$ & $\%$ \\
\hline \multicolumn{3}{|l|}{ Sex } \\
\hline Male & 2,367 & 38.4 \\
\hline Female & 3,789 & 61.6 \\
\hline \multicolumn{3}{|l|}{ Race } \\
\hline Non-Hispanic white & 4,866 & 79.0 \\
\hline Non-Hispanic black & 853 & 13.9 \\
\hline Hispanic & 437 & 7.1 \\
\hline \multicolumn{3}{|l|}{ Education } \\
\hline Less than high school (< 12 years) & 1,396 & 22.7 \\
\hline \multirow[t]{2}{*}{ High school and above ( $\geq 12$ years) } & 4,760 & 77.3 \\
\hline & $M$ & $S D$ \\
\hline Age in 2000 & 64.54 & 7.91 \\
\hline Body mass index & 27.51 & 5.10 \\
\hline State-level SES $¥$ & 7.52 & 1.02 \\
\hline State-level density of fast food restaurants per 100,000 people & 89 & 1.40 \\
\hline State-level percentage of people who walk to work (\%) & 3.45 & 1.56 \\
\hline
\end{tabular}

${ }^{\dagger} T$ The reported percentages are weighted percentages.

${ }^{\ddagger}$ State-level SES is a composite scale score reflecting socioeconomic status for each state and ranges from 3 (the worst) to 12 (the best). 
Table 2 Estimates from the three-level multilevel models for body mass index (BMI), Health and Retirement Study (2000-2010)

\begin{tabular}{|c|c|c|c|c|}
\hline & $\begin{array}{l}\text { Null model } \\
\text { (Model 1) }\end{array}$ & $\begin{array}{l}\text { Unconditional } \\
\text { growth model } \\
\text { (Model 2) }\end{array}$ & $\begin{array}{l}\text { Level-2 } \\
\text { predictors } \\
\text { model } \\
\text { (Model 3) }\end{array}$ & $\begin{array}{l}\text { Level-3 } \\
\text { predictors } \\
\text { model } \\
\text { (Model 4) }\end{array}$ \\
\hline \multicolumn{5}{|l|}{ Intra-person fixed effect (level-1) } \\
\hline Intercept for linear growth rate & & $0.105^{* * *}$ & $0.099 * * *$ & $0.099 * * *$ \\
\hline Intercept for quadratic growth rate & & $-0.008 * * *$ & $-0.008 * * *$ & $-0.008 * * *$ \\
\hline \multicolumn{5}{|l|}{ Individual-level fixed effect (level-2) } \\
\hline Intercept for initial status & $27.670 * * *$ & $27.417 * * *$ & $27.226 * * *$ & $27.240 * * *$ \\
\hline Female & & & $-0.669 * * *$ & $-0.668 * * *$ \\
\hline Age at the baseline & & & $-0.095 * * *$ & $-0.095 * * *$ \\
\hline Education $<12$ years (vs. $\geq 12$ years) & & & $0.662 * * *$ & $0.594 * * *$ \\
\hline Non-Hispanic black (vs. non-Hispanic white) & & & $2.710 * * *$ & $2.419 * * *$ \\
\hline Hispanic (vs. non-Hispanic white) & & & $1.438 * * *$ & $1.465^{* * *}$ \\
\hline \multicolumn{5}{|l|}{ State-level fixed effect (level-3) } \\
\hline State-level SES ${ }^{+}$ & & & & 0.071 \\
\hline State-level density of fast food restaurants & & & & -2.069 \\
\hline State-level \% of people who walk to work & & & & 0.091 \\
\hline \multicolumn{5}{|l|}{ Cross-level interaction (level-1*level-2) } \\
\hline Female ${ }^{*}$ year & & & $0.027 * * *$ & $0.027 * * *$ \\
\hline Age at the baseline $*$ year & & & $-0.009 * * *$ & $-0.009 * * *$ \\
\hline Education year $<12$ years (vs. $\geq 12$ years) $*$ year & & & 0.004 & 0.013 \\
\hline Race, non-Hispanic black (vs. non-Hispanic white) ${ }^{*}$ year & & & $-0.063 * * *$ & $-0.063 * * *$ \\
\hline Race, Hispanic (vs. non-Hispanic white) * year & & & -0.022 & $-0.040 *$ \\
\hline
\end{tabular}




\begin{tabular}{|c|c|c|c|c|}
\hline & $\begin{array}{l}\text { Null model } \\
\text { (Model 1) }\end{array}$ & $\begin{array}{l}\text { Unconditional } \\
\text { growth model } \\
\text { (Model 2) }\end{array}$ & $\begin{array}{l}\text { Level-2 } \\
\text { predictors } \\
\text { model } \\
\text { (Model 3) }\end{array}$ & $\begin{array}{l}\text { Level-3 } \\
\text { predictors } \\
\text { model } \\
\text { (Model 4) }\end{array}$ \\
\hline \multicolumn{5}{|l|}{ Cross-level interaction (level-1*level-3) } \\
\hline State-level SES * year & & & & 0.010 \\
\hline State-level density of fast food restaurants * year & & & & -0.040 \\
\hline State-level \% of people who walk to work * year & & & & 0.005 \\
\hline \multicolumn{5}{|l|}{ Cross-level interaction (level-2*level-3) } \\
\hline Female * state-level SES & & & & $-0.242^{*}$ \\
\hline Age at the baseline $*$ state-level SES & & & & 0.020 \\
\hline $\begin{array}{l}\text { Education }<12 \text { years (vs. } \geq 12 \text { years) } * \text { state-level } \% \text { of people } \\
\text { to work }\end{array}$ & & & & -0.039 \\
\hline $\begin{array}{l}\text { Race, non-Hispanic black (vs. non-Hispanic white) * state-level density of fast } \\
\text { food restaurants }\end{array}$ & & & & -4.386 \\
\hline $\begin{array}{l}\text { Race, non-Hispanic black (vs. non-Hispanic white) * state-level \% of people } \\
\text { who walk to work }\end{array}$ & & & & -0.258 \\
\hline $\begin{array}{l}\text { Race, Hispanic (vs. non-Hispanic white) * state-level density of fast food } \\
\text { restaurants }\end{array}$ & & & & -1.913 \\
\hline $\begin{array}{l}\text { Race, Hispanic (vs. non-Hispanic white) * state-level \% of people who walk to } \\
\text { work }\end{array}$ & & & & 0.060 \\
\hline \multicolumn{5}{|l|}{ Cross-level interaction (level-1*level-2*level-3) } \\
\hline Female * state-level SES * year & & & & -0.010 \\
\hline $\begin{array}{l}\text { Education }<12 \text { years (vs. } \geq 12 \text { years) * state-level \% of people who walk to } \\
\text { work * year }\end{array}$ & & & & 0.015 \\
\hline $\begin{array}{l}\text { Race, Non-Hispanic black (vs. non-Hispanic white) * state-level density of } \\
\text { fast food restaurants * year }\end{array}$ & & & & 0.192 \\
\hline $\begin{array}{l}\text { Race, non-Hispanic black (vs. non-Hispanic white) * state-level \% of people } \\
\text { who walk to work * year }\end{array}$ & & & & -0.015 \\
\hline
\end{tabular}




\begin{tabular}{|c|c|c|c|c|}
\hline & $\begin{array}{l}\text { Null model } \\
\text { (Model 1) }\end{array}$ & $\begin{array}{l}\text { Unconditional } \\
\text { growth model } \\
\text { (Model 2) }\end{array}$ & $\begin{array}{l}\text { Level-2 } \\
\text { predictors } \\
\text { model } \\
\text { (Model 3) }\end{array}$ & $\begin{array}{l}\text { Level-3 } \\
\text { predictors } \\
\text { model } \\
\text { (Model 4) }\end{array}$ \\
\hline $\begin{array}{l}\text { Race, Hispanic (vs. non-Hispanic white) * state-level density of fast food } \\
\text { restaurants * year }\end{array}$ & & & & -0.122 \\
\hline $\begin{array}{l}\text { Race, Hispanic (vs. non-Hispanic white) * state-level \% of people who walk to } \\
\text { work * year }\end{array}$ & & & & $-0.033 * * *$ \\
\hline \multicolumn{5}{|l|}{ Random effect (variance component) } \\
\hline Level-1 temporal variation & 3.560 & 2.177 & 2.178 & 2.178 \\
\hline Level-2 individual initial status & $25.272 * * *$ & $23.919 * * *$ & $22.262 * * *$ & $22.157 * * *$ \\
\hline Level-2 individual linear growth rate & & $0.177^{* * *}$ & $0.172^{* * *}$ & $0.172^{* * *}$ \\
\hline Level-2 individual quadratic growth rate & & $0.002 * * *$ & $0.002 * * *$ & $0.002 * * *$ \\
\hline Level-3 state initial status & $2.338^{* * *}$ & $2.108 * * *$ & $2.051 * * *$ & $1.189 * * *$ \\
\hline Level-3 state linear growth rate & & & & 0.001 \\
\hline \multicolumn{5}{|l|}{ Model fit } \\
\hline Deviance (-2 log likelihood) & 168717.2 & 163884.8 & 163124.4 & 163080.5 \\
\hline AIC & 168725.2 & 163906.8 & 163166.4 & 163164.5 \\
\hline \multicolumn{5}{|l|}{ Hierarchical model testing ${ }^{\ddagger}$} \\
\hline$\chi^{2}$ value & & $4,832.4$ & 760.4 & 43.9 \\
\hline$p$ value & & $<.001$ & $<.001$ & $<.01$ \\
\hline
\end{tabular}

${ }^{+}$State-level SES is a composite scale score reflecting socioeconomic status for each state and ranges from 3 (worst) to 12 (best).

${ }^{\ddagger}$ Each model was compared to the immediate previous model. vs. $=$ versus

$* p<.05,{ }^{* *} p<.01, * * * p<.001$ 